\title{
Ki67 is a promising molecular target in the diagnosis of cancer (Review)
}

\author{
LIAN TAO LI* , GUAN JIANG* ${ }^{*}$, QIAN CHEN and JUN NIAN ZHENG \\ Jiangsu Key Laboratory of Biological Cancer Therapy, Xuzhou Medical College, Xuzhou, Jiangsu 221002, P.R. China
}

Received January 13, 2014; Accepted July 31, 2014

DOI: $10.3892 / \mathrm{mmr} .2014 .2914$

\begin{abstract}
The expression of Ki67 is strongly associated with tumor cell proliferation and growth, and is widely used in routine pathological investigation as a proliferation marker. The nuclear protein Ki67 (pKi67) is an established prognostic and predictive indicator for the assessment of biopsies from patients with cancer. Clinically, pKi67 has been shown to correlate with metastasis and the clinical stage of tumors. In addition, it has been shown that Ki67 expression is significantly higher malignant tissues with poorly differentiated tumor cells, as compared with normal tissue. According to its predictive role, pKi67 expression identifies subpopulations of patients who are more likely to respond to a given therapy. The Ki67 labeling index is an independent prognostic factor for survival rate, which includes all stages and grade categories. There is a correlation between the ratio of Ki67-positive malignant cells and patient survival. It has been shown that blocking of Ki67 either by microinjection of antibodies or through the use of antisense oligonucleotides leads to the arrest of cell proliferation. Specifically, antisense oligonucleotides and antibodies against pKi67 have been shown to inhibit the progression of the cell cycle. The Ki67 protein is well characterized at the molecular level and is extensively used as a prognostic and predictive marker for cancer diagnosis and treatment. Increasing evidence indicates that Ki67 may be an effective target in cancer therapy. It therefore merits further development, including testing in more sophisticated in vitro and appropriate in vivo models. This review provides an overview of recent advances in this field.
\end{abstract}

Correspondence to: Dr Jun Nian Zheng, Jiangsu Key Laboratory of Biological Cancer Therapy, Xuzhou Medical College, 84 West Huaihai Road, Xuzhou, Jiangsu 221002, P.R. China

E-mail: jnzheng@xzmc.edu.cn

*Contributed equally

Key words: Ki67, molecular target, cancer diagnosis

\section{Contents}

1. Introduction

2. Characteristics of pKi67

3. Scoring and methodology

4. pKi67 as a diagnostic tool

5. pKi67 as a prognostic tool

6. Ki-67 as a potential therapeutic target for cancer therapy

7. Conclusion

\section{Introduction}

The Ki67 antigen, which encodes two protein isoforms with molecular weights of 345 and $395 \mathrm{kDa}$, was originally identified by Scholzer and Gerdes in the early 1980s (1). The Ki67 protein has a half-life of only $\sim 1-1.5 \mathrm{~h}$. It is present during all active phases of the cell cycle (G1, S, G2 and M), but is absent in resting cells $(\mathrm{G} 0)(2,3)$. In later phases of mitosis (during anaphase and telophase), a sharp decrease in Ki67 levels occurs (4). Expression of the Ki67 protein (pKi67) is associated with the proliferative activity of intrinsic cell populations in malignant tumors, allowing it to be used as a marker of tumor aggressiveness $(5,6)$. The prognostic value of pKi67 has been investigated in a number of studies with its potential as a reliable marker having been shown in cancers of the breast, soft tissue, lung, prostate, cervix and central nervous system (7-11).

Current classification schemes may require revision where biological behavior and prognostic significance of these tumors is concerned, as an increasing number of studies have suggested that Ki67 may be an important factor in cancer grading and prognostic evaluation. It has been shown that Ki67 immunohistochemical (IHC) staining is an effective method of assessing the prognosis in a number of tumor types $(12,13)$.

Although pKi67 is a key marker associated with proliferating cancer cells and a poor prognosis, its full potential in increasing proliferation has not been evaluated. In syngeneic animal models with subcutaneous or orthotopic bladder cancer, prostate cancer or renal cell carcinoma, antisense oligonucleotides induced tumor growth inhibition $(14,15)$, potentially through the inhibition of Ki-67, indicating the involvement of Ki67 in tumor cell proliferation.

This review provides an update on the current knowledge of Ki67 and the evidence regarding the prognostic and predic- 
tive role of this marker (Fig. 1). It also discusses the laboratory techniques used to determine Ki67 levels.

\section{Characteristics of pKi67}

The Ki67 antigen was originally identified in the 1980s, as a proliferation-associated nuclear antigen, which is only detected in dividing cells (G1-, S-, G2- and M-phase) and not in quiescent cells (G0 phase) (16). Ki67 levels are low in the G1 and S phases and peak early in mitosis. In later phases of mitosis, a sharp decrease in Ki67 levels occurs (17). The gene encoding Ki67 is a continuous sequence of 29,965-bp length located on chromosome 10q25-ter and is comprised of 15 exons with sizes ranging from 67 to $6845 \mathrm{bp}$ and 14 introns with sizes ranging from 87 to 3569 bp. Exon 13 contains 16 homologous segments of $366 \mathrm{bp}$ (Ki67 repeats) located at the center of this gene. The complete gene is comprised of a $74 \mathrm{bp}$ 5 ' region and a 264 bp 3' region in the Ki67 protein (18-20).

The quantity of pKi67 present at any time during the cell cycle is regulated by a precise balance between synthesis and degradation, as indicated by its short half life of 1-1.5 h (20,21). Ki67 protein expression coincides with the transit of cells through mitosis and undergoes phosphorylation and dephosphorylation during mitosis in vivo, rendering it susceptible to protease degradation. Furthermore, its structure indicates that its expression is regulated by proteolytic pathways, such as those controlled by the key regulatory complex cyclin $\mathrm{B} /$ cyclin-dependent kinase $2(1,22)$. pKi67 is known to share structural similarities (including a so-called fork head-associated domain) with other proteins, such as DUN1 and RAD, which are involved in cell cycle regulation (23).

The characterization of the Ki67 promoter region is essential for understanding gene transcription, and it is therefore important to investigate this in order to develop targeted interventions aimed at modulating gene expression (24). In a previous study, deletion analysis and a dual luciferase reporter assay were used to locate the Ki-67 core promoter from -223 to $+12 \mathrm{nt}$ relative to the transcriptional initiation site, which is a TATA less, GC rich region comprised of several putative $\mathrm{Sp} 1$ binding sites. It was demonstrated that the region from -223 to +12 nt could drive the transcription of the Ki-67 gene, and that the Sp1 binding site is essential for the transcriptional regulation of the Ki-67 gene. (25). An electrophoretic mobility shift assay revealed three Sp1-binding sites in the Ki67 promoter that are essential for its basal transcriptional activity.

It was found that expression of p53 is correlated with that of Ki67 in several types of cancer, including oral squamous cell cancer and breast cancer (26). How p53 may affect Ki67 gene expression is not yet clear. As there are three Sp1-binding sites in the Ki67 promoter and as p53 represses the transcription of genes at Sp1-binding sites of promoters $(20,26,27)$, it is likely that p53 inhibits Ki67 promoter activity via p53- and Sp1-dependent pathways. It is hypothesized that there are at least two transcriptional regulatory mechanisms. One is that the p53-binding motifs affect the transcriptional repression of the Ki67 promoter. The other is a possible interaction between $\mathrm{p} 53$ and $\mathrm{Sp1}$ at Sp1-binding sites on the Ki67 promoter.

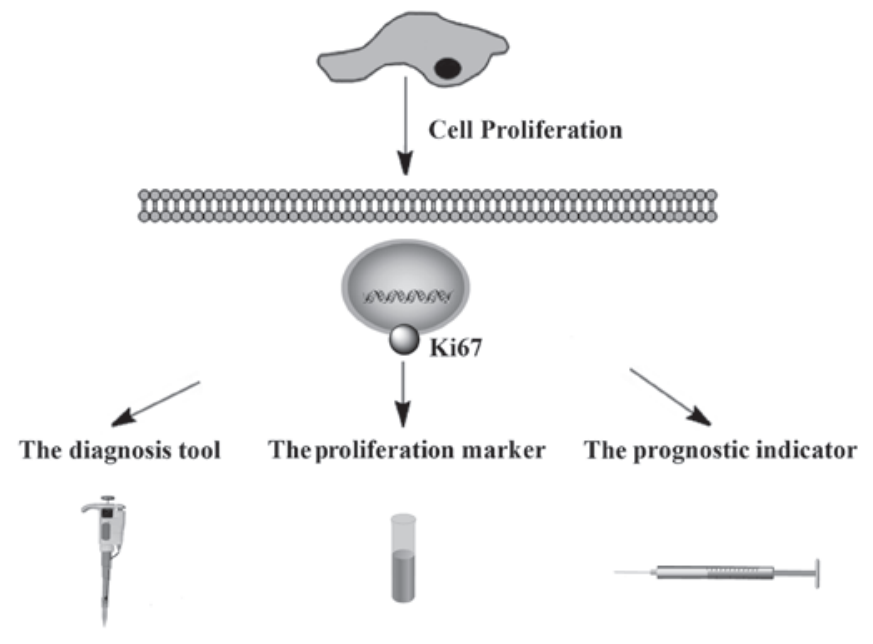

Figure 1. Schematic diagram of Ki67 as a promising molecular target in the diagnosis of cancer. The expression of Ki-67 is strictly associated with tumor cell proliferation and growth, and is widely used in routine pathology as a proliferation marker and a diagnosis tool. The nuclear protein Ki-67 (pKi-67) is an established prognostic and predictive indicator for the assessment of cell proliferation in biopsies from cancer patients.

\section{Scoring and methodology}

Scoring systems are based on the percentage of tumor cells stained by an antibody. In order to assess the methodology of a study, a publication is scored using The World Health Organization's classification system (28). The score is determined by various aspects of methodology, which are grouped into three main categories: The scientific design, the description of the laboratory methods used to identify the presence of pKi67, DNA/RNA or antibodies against Ki67 (29,30), and some clinical reports that have used the techniques for Ki67 detection (31-34). Briefly, an automated bright-field microscope and software are used to detect and classify. After the Ki67-stained slide has been scanned at x 5 magnification, a trained clinical laboratory scientist, who is blinded to the histological diagnoses and patient survival data, randomly selects at least eight fields representative of the range of Ki67 immunostaining in the previously encircled tumor for evaluation with an automated bright-field microscope at x20 (35). The percentage of Ki-67-positive tumor nuclei (Ki-67 index) was quantitated for each case using the Ariol ${ }^{\circledR}$ SL-50 Image Analyzer and imaging software (Genetix Corp, Boston, MA, USA)

Multiple clinical laboratories have reported the successful use of Ki67 as a diagnostic tool (36-39). Expression of Ki67, as evaluated by immunostaining has become the gold standard, with a cutoff level of between 10 and $14 \%$ positively-stained cells defined as high risk in terms of prognosis (40-42). The St Gallen Consensus in 2009 considered the Ki-67 labelling index important for selecting the addition of chemotherapy to endocrine therapy in hormone receptor-positive breast cancers. In addition, tumors may be classified as low, intermediate, and highly proliferating, according to the Ki-67 labelling index of $\leq 15 \%, 16 \%-30 \%$, and $>30 \%$, respectively (43). Tissue microarray technology has become increasingly important over the past decade. There are concerns with the scoring reliability of tissue microarrays due to tumor heterogeneity. To 
overcome this issue, certain experts have used multiple cores when conducting this analysis $(44,45)$. However, a number of pathologists have expressed the view that using a manual counting procedure will obtain a more reliable score, which may lead to differences in interpretation between examiners with consequent variability in diagnoses (46). By contrast, reverse transcription-quantitative polymerase chain reaction assays, with convenient quantification of target transcripts, result in objective and continuous data variables.

Nowadays, formalin-fixed paraffin-embedded tissue samples are routinely used for gene expression analysis, which can aid in overcoming technical difficulties (47-50). The use of formalin-fixed, paraffin-embedded (FFPE) tissue overcomes the most prominent issues related to research on relatively rare diseases: limited sample size, availability of control tissue, and time frame.

FFPE samples are easy to handle and store and are suitable for diagnostic histology, immunohistochemistry, and in situ hybridization. Therefore, this sample type is almost always available for diseases in which treatment involves surgery to remove parts of or almost the entire affected organ. Furthermore, invaluable clinical information and follow-up data are often accessible in conjunction with FFPE samples (3). Lastly, the tissue is usually available in amounts adequate for use in GEM studies and obtained biologically relevant and disease-specific, significant genes; cancer-related genes.

\section{4. pKi67 as a diagnostic tool}

$\mathrm{Ki} 67$ is frequently used as an indicator of cell proliferation (51,52). A number of diagnostic applications for pKi67 have been described, where Ki67 was significantly more highly expressed in malignant than in normal tissues $(53,54)$. pKi67 also tended to increase with decreasing tissue differentiation, and it was correlated with the presence of occult metastasis and the clinical stage of tumors (55-58). Proliferative activity in tumors can be determined by mitotic counting, flow-cytometric determination of synthesis-phase fraction and immunohistochemistry using antibodies reactive against various proliferating cellular antigens. The Ki67/MIB-1 monoclonal antibody is commonly used, and is reactive against the nuclear antigen $\mathrm{Ki} 67$ that is expressed during cell cycle phases G1, S, G2 and M, but is not found during G0 $(27,59,60)$. The percentage of immunoreactive tumor cell nuclei is expressed as a labeling index (LI). Studies thus far have all shown a positive correlation between Ki67/MIB-1 LI and tumor grade in human malignancy. Due to the limitations of routine histological examination of tumor tissue in predicting tumor behavior, Ki67/MIB-1 immunostaining has been introduced for its potential to improve the information provided by the grading system $(27,61)$. Its presence in a variety of tumors indicates that it may be possible to use $\mathrm{Ki} 67$ in routine grading of cancer (62-65). Judicious use of this proliferation marker in combination with established histopathological features of malignancy may serve as a more reliable indicator of the likelihood of tumor recurrence (66).

The data on Ki67 as a diagnostic marker is scarce and based on varying laboratory and statistical methods. Cancer has a complex pathogenesis and reliable early diagnosis is difficult. Symptoms usually do not appear until the disease has progressed to an advanced stage. Therefore, further research into diagnostic and prognostic markers may aid early diagnosis. Notably, the expression of Ki67 reflects the tumor proliferation rate and correlates with initiation, progression, metastasis and prognosis of a number of types of tumors $(18,67-72)$. Certain regulators of these processes, such as Smac (73-76), minichromosome maintenance 7 (77), p53 (10,78-80), Bcl-2 (81), proliferating cell nuclear antigen (PCNA) (75) and CD105 (82) have been investigated. In a number of studies, Ki67 appeared to be closely correlated with pancreatic tumor severity as well as with expression of Smac and thus may be useful as a diagnostic and prognostic marker or, in conjunction with Smac, as an indicator of treatment efficacy (73-75). In a further study, Chen et al (83) reported that utilizing Ki67 LI and vascular endothelial growth factor scoring is useful to effectively and accurately predict outcomes and optimize personal therapy in judging the outcomes of non-muscle invasive bladder cancer This novel molecular grading system could enhance the efficiency of the conventional system.

Colorectal carcinoma is the fourth leading cause of cancer-related mortality worldwide (84). It has been demonstrated that the Ki67 LI was higher in Dukes' stage B than in Dukes' stage $\mathrm{C}$ carcinoma. They concluded that the positive rate of Ki-67 antibody in poorly differentiated adenocarcinoma and mucinous carcinomas was significantly lower than in well differentiated and moderately differentiated adenocarcinomas, suggesting that proliferative activity is low in cancers with poor differentiation. On the other hand, it has been demonstrated that the Ki-67 LI is high in well to moderately differentiated, non-mucinous adenocarcinomas in an early Dukes' stage (A or B) as compared with that in poorly differentiated, mucinous adenocarcinomas or signet-ring cell colorectal carcinomas in an advanced Dukes' stage (C). MIB-1 is a monoclonal antibody that recognizes a fixation resistant epitope of the Ki67 antigen and it is used to estimate the proliferative fraction of neoplasia (85). Using MIB-1, it was observed that Ki67 LI was high in Grade I and Grade II as compared with the Grade III carcinomas.

The Ki67 index is a diagnostic and prognostic aid in several fields of pathology and an established predictive tool in others (37,86-90). However, existing Ki67 index estimations are time-consuming and cumbersome, and may be subject to inter-observer variability (90-93). To improve the accuracy of the Ki67 index, current research recommends the use of an IHC cocktail, which detects Ki67 and the melanocytic marker, melanoma antigen recognized by T cells (MART1) (94). In melanocytic pathology, current research favors using Ki67/MART1 double stains to accurately distinguish Ki67-positive melanocytic cells from other proliferating Ki67-positive cells, including lymphocytes, stromal cells and epithelial cells $(95,96)$. The usability and cost benefit of automated MART1-verified Ki67 indices in routine settings require investigation in a prospective study with a consecutive inclusion of specimens. When predicting a clinical outcome for the individual patient, automated MART1-verified Ki67 indices may be more reliable as a result of a reduction in false positive results with this assay.

\section{5. pKi67 as a prognostic tool}

It is known that $\mathrm{Ki} 67$ is expressed in all cell-cycle phases outside of the resting phase G0. Academics recommend its use 
as a prognostic marker over mitotic rate (97-100). A number of studies have shown a correlation between proliferative markers and tumor grade $(13,82,101)$. Studies have also suggested a predictive role for $\mathrm{pKi} 67$, in that an individual patient may be treated with a specific regimen based on the degree of pKi67 expression (78). While a prognostic biomarker indicates the likely course of the disease in an untreated individual, a predictive biomarker identifies subpopulations of patients who are most likely to respond to a given therapy. The results of one study indicated that the Ki67 labeling index is an independent prognostic factor for survival rate, including all stage and grade categories (102). Studies demonstrated a correlation between the ratio of Ki67-positive malignant cells and patient survival $(103,104)$. Vogt and Klapper (105) showed that the Ki67 index was associated with prognosis in specimens from patients with primary and relapsed mantle cell lymphoma in the large cohort, which was included in the first of a number of studies on MCLs. The pretherapeutic assessment of Ki67 expression is becoming more important in the evaluation of tumor aggressiveness and the selection of adequate treatment.

In a number of tumors there appears to be a degree of correlation between pKi67 expression and patient survival, e.g. cervical and uterine cancer, non-Hodgkin's lymphoma and large bowel cancer $(106,107)$. Indeed, Kimura et al (6) found that cases of colorectal carcinoma showing a high pKi67 expression at the site of deepest invasion had a worse prognosis. These findings may be the result of the marked heterogeneity of pKi67 expression in carcinomas. Numerous studies have similarly confirmed the utility of the Ki67 proliferation index as a prognostic indicator in cancer, as it shows a correlation with primary tumor size, lymphatic invasion, metastases, tumor proliferation activity measured by DNA flow cytometry and shorter patient survival times.

Mucosal malignant melanoma (MMM) of the sinonasal tract accounts for $1 \%$ of all mucosal melanomas and 3-4\% of malignant neoplasms of the sinonasal tract (108). Intense immunohistochemical staining for Ki67 is correlated with a poor prognosis in various malignancies $(95,109,110)$. One study reported that scores of $\leq 40 \%$ for $\mathrm{Ki} 67$ and $\leq 80 \%$ for PCNA were correlated with good prognosis in anorectal malignant melanoma $(74,111)$. Another study showed that scores of $\leq 20 \%$ for Ki67 and $\leq 35 \%$ for PCNA were correlated with a good prognosis in cutaneous malignant melanoma $(84,112)$. These studies showed that Ki67 is negatively correlated with a more favorable prognosis, which indicates that the Ki67 antigen may be useful as a diagnostic and prognostic factor for MMM.

\section{Ki-67 as a potential therapeutic target for cancer therapy}

Ki-67 is a sensitive protein associated with cell proliferation. Owing to high cell proliferation, frequently associated with the $\mathrm{Ki}-67$ protein labeling index, $\mathrm{Ki} 67$ may be a promising factor for targeted molecular therapies.

Antisense oligodeoxynucleotides (ASOs) have been studied as specific tools for treating tumors $(14,113)$. In syngeneic animal models, Ki-67-ASOs markedly inhibit tumour growth $(114,115)$. However, there are several factors that effect their application, including nuclease degradation (116). In order to improve the characteristics of ASOs, the development of their derivatives requires promotion, particularly that of peptide nucleic acids
(PNAs) (117). PNAs are a DNA mimic that can target DNA and RNA with high specifically and affinity $(105,118,119)$. In vitro, anti-K-67 PNAs yielded a stronger inhibitive effect on Ki-67 expression than ASOs, and had greater effects on the proliferation and apoptosis of human renal carcinoma cells (115).

In recent years a new technique, known as RNA interference (RNAi), has been developed, which suppresses gene expression mediated by siRNAs (120). siRNA-inhibition of Ki-67 expression has been shown to lead to significant inhibition of proliferation $(14,121)$. While synthetic siRNAs can rapidly knock down target genes and achieve similar effects, the result is transient (73). The most significant obstacles in the use of siRNAs are efficient uptake and long-term stability (122). To resolve these problems, certain studies have investigated the transfection of plasmid vectors to stably synthesize so-called "short hairpin RNAs" (shRNAs) in host cells, which makes it possible alter native cell processes (123-125).

Concurrently, another study constructed a novel oncolytic adenovirus-based shRNA expression system named ZD55, an E1B 55kDa-deficient oncolytic adenovirus that is similar to ONYX-015 (126), which has the ability to deliver Ki-67- shRNA and the lytic ability of oncolytic adenoviruses. ZD55-Ki67 induces silencing of the Ki-67 gene, allowing for efficient tumor-specific viral replication and inducing the apoptosis of tumor cells in vitro and in nude mice (127).

Furthermore, the microinjection of antibodies directed against the Ki-67 was shown to result in a decreased rate of cell division $(128,129)$. In this technique, the nuclear localization presents a major hurdle, due to the need for intracellular and intranuclear delivery of targeting and therapeutic moieties. Zhang et al (129) used a liposomally encapsulated construct to design photo immunoconjugate-encapsulating liposomes (PICELs). Non-cationic PICELs are particularly useful for the subcellular delivery of mAbs and provide multi-functional constructs for imaging and therapy.

In summary, due to its ubiquitous expression in all proliferating cells and the prognostic value of the $\mathrm{Ki}-67$ index in many cancers, pKi-67 is an potentially attractive therapeutic target in cancer, and strategies that inactivate $\mathrm{pKi}-67$ are a promising anti-proliferative approach, with potentially broad applicability in cancer treatment (14). Hence, targeting pathways and molecular markers implicated in cancer cell growth is a promising avenue for the development of effective therapies.

\section{Conclusion}

As a proliferation marker to measure the growth fraction of cells in human tumors, the expression of $\mathrm{Ki} 67$ is strongly associated with cell proliferation and is widely used in routine pathology. pKi67 is well characterized at the molecular level and extensively used as a prognostic and predictive marker in cancer. Based on the studies presented here, Ki67 may be a promising molecular candidate for the diagnosis and treatment of a wide range of malignancies.

\section{Acknowledgements}

This study was supported by grants from the National Natural Science Foundation of China (grant nos. 81372916, 81372460 and 81101702), the Science and Technology Department of 
Xuzhou city (grant no. XM13B084), the 'Six Talent Peaks' Project of Jiangsu Province (grant no. 2013-WSN-014), the Key University Science Research Project of Jiangsu Province (grant nos. 11KJA320002, 12KJA320001 and 11KJB320017) and the Science and Technology Department of Jiangsu province (grant nos. BK20141142, BK2013348 and BK2011207).

\section{References}

1. Scholzen T and Gerdes J: The Ki-67 protein: from the known and the unknown. J Cell Physiol 182: 311-322, 2000.

2. Shirendeb U, Hishikawa Y, Moriyama S, et al: Human papillomavirus infection and its possible correlation with p63 expression in cervical cancer in Japan, Mongolia, and Myanmar. Acta Histochem Cytochem 42: 181-190, 2009.

3. Hooghe B, Hulpiau P, Van Roy F and De Bleser PD: ConTra: a promoter alignment analysis tool for identification of transcription factor binding sites across species. Nucleic Acids Res 36: W128-W132, 2008.

4. Modlin IM, Moss SF, Chung DC, et al: Priorities for improving the management of gastroenteropancreatic neuroendocrine tumors. J Natl Cancer Inst 100: 1282-1289, 2008.

5. Klöppel G, Perren A and Heitz PU: The gastroenteropancreatic neuroendocrine cell system and its tumors: the WHO classification. Ann N Y Acad Sci 1014: 13-27, 2004.

6. Brown DC and Gatter KC: Ki67 protein: the immaculate deception? Histopathology 40: 2-11, 2002.

7. Ishihara M, Mukai H, Nagai S, et al: Retrospective analysis of risk factors for central nervous system metastases in operable breast cancer: effects of biologic subtype and Ki67 overexpression on survival. Oncology 84: 135-140, 2013

8. Sorbye SW, Kilvaer TK, Valkov A, et al: Prognostic impact of Jab1, p16, p21, p62, Ki67 and Skp2 in soft tissue sarcomas. PLoS One 7: e47068, 2012.

9. Sorbye SW, Kilvaer TK, Valkov A, et al: Prognostic impact of CD57, CD68, M-CSF, CSF-1R, Ki67 and TGF-beta in soft tissue sarcomas. BMC Clin Pathol 12: 7, 2012.

10. Ciancio N, Galasso MG, Campisi R, et al: Prognostic value of p53 and Ki67 expression in fiberoptic bronchial biopsies of patients with non small cell lung cancer. Multidiscip Respir Med 7: 29, 2012 .

11. Josefsson A, Wikström P, Egevad L, et al: Low endoglin vascular density and Ki67 index in Gleason score 6 tumours may identify prostate cancer patients suitable for surveillance. Scand J Uro Nephrol 46: 247-257, 2012.

12. Iatropoulos MJ and Williams GM: Proliferation markers. Exp Toxicol Pathol 48: 175-181, 1996.

13. Jacquemier JD, Penault-Llorca FM, Bertucci F, et al: Angiogenesis as a prognostic marker in breast carcinoma with conventional adjuvant chemotherapy: a multiparametric and immunohistochemical analysis. J Pathol 184: 130-135, 1998.

14. Kausch I, Lingnau A, Endl E, et al: Antisense treatment against Ki-67 mRNA inhibits proliferation and tumor growth in vitro and in vivo. Int J Cancer 105: 710-716, 2003.

15. Liu J, Fang L, Cheng Q, et al: Effects of G250 promoter controlled conditionally replicative adenovirus expressing Ki67-siRNA on renal cancer cell. Cancer Sci 103: 1880-1888, 2012.

16. Gerlach C, Sakkab DY, Scholzen T, et al: Ki-67 expression during rat liver regeneration after partial hepatectomy. Hepatology 26 573-578, 1997.

17. Le Guellec S, Perallon R, Alunni JP, et al: Neoadjuvant treatment of breast cancer: implications for the pathologist. Ann Pathol 31: 442-454, 2011 (In French)

18. Yerushalmi R, Woods R, Ravdin PM, et al: Ki67 in breast cancer: prognostic and predictive potential. Lancet Oncol 11: 174-183, 2010.

19. Duchrow M, Schlüter C, Wohlenberg C, et al: Molecular characterization of the gene locus of the human cell proliferation-associated nuclear protein defined by monoclonal antibody Ki-67. Cell Prolif 29: 1-12, 1996.

20. Halm U, Tannapfel A, Breitung B, et al: Apoptosis and cell proliferation in the metaplasia-dysplasia-carcinoma-sequence of Barrett's esophagus. Hepatogastroenterology 47: 962-966, 2000.

21. Rahmanzadeh R, Hüttmann G, Gerdes J and Sholzen T: Chromophore-assisted light inactivation of pKi67 leads to inhibition of ribosomal RNA synthesis. Cell Prolif 40: 422-430, 2007.
22. Castro LA, Elias LS, Oton-Leite AF, et al: Long-term effects of nifedipine on human gingival epithelium: a histopathological and immunohistochemical study. J Oral Sci 52: 55-62, 2010.

23. Panteva MT, Salari R, Bhattacharjee M and Chong LT: Direct observations of shifts in the $\beta$-sheet register of a protein-peptide complex using explicit solvent simulations. Biophys J 100: L50-L52, 2011.

24. Tian H, Qian GW, Li W, et al: A critical role of Sp1 transcription factor in regulating the human Ki-67 gene expression. Tumour Biol 32: 273-283, 2011.

25. Chen F, Song J, Di J, et al: IRF1 suppresses Ki-67 promoter activity through interfering with $\mathrm{Sp1}$ activation. Tumour Biol 33: 2217-2225, 2012

26. Nakano T, Ohno T, Ishikawa $\mathrm{H}$, et al: Current advancement in radiation therapy for uterine cervical cancer. J Radiat Res 51: $1-8,2010$

27. Kim BH, Bae YS, Kim SH, et al: Usefulness of Ki-67 (MIB-1) immunostaining in the diagnosis of pulmonary sclerosing hemangiomas. APMIS 121: 105-110, 2013.

28. Steels E, Paesmans M, Berghmans T, et al: Role of p53 as a prognostic factor for survival in lung cancer: a systematic review of the literature with a meta-analysis. Eur Respir J 18: 705-719, 2001.

29. Martin B, Paesmans M, Mascaux C, et al: Ki-67 expression and patients survival in lung cancer: systematic review of the literature with meta-analysis. Br J Cancer 91: 2018-2025, 2004.

30. Faes T, Pecceu A, Van Calenbergh S and Moerman P: Chorangiocarcinoma of the placenta: a case report and clinical review. Placenta 33: 658-661, 2012

31. Almeida JC, Menezes RP, Kuckelhaus SA, Bocca AL and Figueiredo F: Prognostic value of morphologic and clinical parameters in pT2 - pT3 prostate cancer. Int Braz J Urol 33: 662-672, 2007.

32. Vaira V, Fedele G, Pyne S, et al: Preclinical model of organotypic culture for pharmacodynamic profiling of human tumors. Proc Natl Acad Sci USA 107: 8352-8356, 2010.

33. Hofman MS and Hicks RJ: Changing paradigms with molecular imaging of neuroendocrine tumors. Discov Med 14: 71-81, 2012.

34. Laurinavicius A, Plancoulaine B, Laurinaviciene A, et al: A methodology to ensure and improve accuracy of Ki67 labelling index estimation by automated digital image analysis in breast cancer tissue, Breast Cancer Res 16: R35, 2014.

35. Hayashi Y, Takei H and Kurosumi M: Ki67 immunohistochemical staining: the present situation of diagnostic criteria. Nihon Rinsho 7: 428-432, 2012 (In Japanese)

36. Zizi-Sermpetzoglou A, Moustou E, Petrakopoulou N, et al: Atypical polypoid adenomyoma of the uterus. A case report and a review of the literature. Eur J Gynaecol Oncol 33: 118-121, 2012.

37. Zini L, Porpiglia F and Fassnacht M: Contemporary management of adrenocortical carcinoma. Eur Urol 60: 1055-1065, 2011

38. Viale G: Pathological work up of the primary tumor: getting the proper information out of it. Breast 20 (Suppl 3): S82-S86, 2011.

39. Leong AS and Zhuang Z: The changing role of pathology in breast cancer diagnosis and treatment. Pathobiology 78: 99-114, 2011.

40. Ibrahim T, Farolfi A, Scarpi E, et al: Hormonal receptor, human epidermal growth factor receptor-2, and Ki67 discordance between primary breast cancer and paired metastases: Clinical impact. Oncology 84: 150-157, 2013.

41. Chlebowski RT, Col N, Winer EP, et al; American Society of Clinical Oncology Breast Cancer Technology Assessment Working Group: American Society of Clinical Oncology technology assessment of pharmacologic interventions for breast cancer risk reduction including tamoxifen, raloxifene, and aromatase inhibition. J Clin Oncol 20: 3328-3343, 2002

42. Blancato J, Singh B, Liu A, Liao DJ and Dickson RB: Correlation of amplification and overexpression of the c-myc oncogene in high grade breast cancer: FISH, in situ hybridization and immunohistochemical analysis. Br J Cancer 90: 1612-1619, 2004.

43. Jonat $\mathrm{W}$ and Arnold $\mathrm{N}$ : Is the Ki-67 labelling index ready for clinical use? Ann Oncol 22: 500-502, 2011.

44. Sapino A, Marchiò C, Senetta R, et al: Routine assessment of prognostic factors in breast cancer using a multicore tissue microarray procedure. Virchows Arch 449: 288-296, 2006.

45. Camp RL, Neumeister V and Rimm DL: A decade of tissue microarrays: progress in the discovery and validation of cancer biomarkers. J Clin Oncol 26: 5630-5637, 2008.

46. Konsti J, Lundin M, Joensuu H, et al: Development and evaluation of a virtual microscopy application for automated assessment of Ki-67 expression in breast cancer. BMC Clin Pathol 11: 3, 2011. 
47. Klimowicz AC, Bose P, Nakoneshny SC, et al: Basal Ki67 expression measured by digital image analysis is optimal for prognostication in oral squamous cell carcinoma. Eur J Cancer 48: 2166-2174, 2012

48. Sánchez-Navarro I, Gámez-Pozo A, González-Barón M, et al: Comparison of gene expression profiling by reverse transcription quantitative PCR between fresh frozen and formalin-fixed, paraffin-embedded breast cancer tissues. Biotechniques 48 : 389-397, 2010

49. Farragher SM, Tanney A, Kennedy RD and Paul Harkin D: RNA expression analysis from formalin fixed paraffin embedded tissues. Histochem Cell Biol 130: 435-445, 2008.

50. Mittempergher L, de Ronde JJ, Nieuwland M, et al: Gene expression profiles from formalin fixed paraffin embedded breast cancer tissue are largely comparable to fresh frozen matched tissue. PLoS One 6: e17163, 2011.

51. Karamitopoulou E, Perentes E, Tolnay $M$ and Probst A: Prognostic significance of MIB-1, p53, and bcl-2 immunoreactivity in meningiomas. Hum Pathol 29: 140-145, 1998.

52. Geyer FC, Rodrigues DN, Weigelt B and Reis-Filho JS Molecular classification of estrogen receptor-positive/luminal breast cancers. Adv Anat Pathol 19: 39-53, 2012

53. Claudio PP, Zamparelli A, Garcia FU, et al: Expression of Cell-Cycle-regulated Proteins pRb2/p130, p107, p27kip1, p53, mdm-2, and Ki-67 (MIB-1) in Prostatic Gland Adenocarcinoma1. Clin Cancer 8:1808-15, 2002.

54. HY Hu, Liu H, JW Zhang, et al: Clinical significance of Smac and Ki-67 expression in pancreatic cancer. Hepato-gastroenterology 59:2640-2643, 2012

55. McCormick D, Chong H, Hobbs C, et al.: Detection of the Ki-67 antigen in fixed and wax-embedded sections with the monoclonal antibody MIB-1. Histopathology 22:355-360, 1993.

56. Merkel D, Dresseler L, McGuire WL: Flow cytometry, cellular DNAcontent, and prognosis in human malignancy. J Clin Oncol 5:1690-1703,1987

57. Clark GM, Mathieu M-C, Owens MA, et al: Prognostic significance of S-phase fraction in good-risk, node-negative breast cancer patients. J Clin Oncol 10:428-432, 1992

58. Fernandez EB, Sesterhenn IA, McCarthy WF, et al: Proliferating cellnuclear antigen expression to predict occult disease in clinical stage Inonseminomatous testicular germ cell tumors. J Urol 152:1133-1138, 1994.

59. de Aguiar PH, Aires R, Laws ER, et al: Labeling index in pituitary adenomas evaluated by means of MIB-1: is there a prognostic role? A critical review. Neurol Res 32: 1060-1071, 2010

60. Prayson RA: The utility of MIB-1/Ki-67 immunostaining in the evaluation of central nervous system neoplasms. Adv Anat Pathol 12: 144-148, 2005.

61. Lind-Landström T, Habberstad AH, Sundstrøm S and Torp SH Prognostic value of histological features in diffuse astrocytomas WHO grade II. Int J Clin Exp Pathol 5: 152-158, 2012.

62. Nabi U, Nagi AH, Sami W: Ki-67 proliferating index and histological grade, type and stage of colorectal carcinoma. J Ayub Med Coll Abbottabad. 20(4):44-8, 2008.

63. Hegazy A, Daoud SA, Ibrahim WS: Role of Ki-67, P53 and Bcl-2 in Advanced Colorectal Carcinoma. Academic Journal of Cancer Research 7 (3): 168-172, 2014.

64. Inwald EC, Klinkhammer-Schalke M, Hofstädter F: Ki-67 is a prognostic parameter in breast cancer patients: results of a large population-based cohort of a cancer registry. Breast Cancer Res Treat 139(2):539-52, 2013.

65. Klöppel G, Perren A, Heiitz PU. The gastroenteropancreatic neuroendocrine cell system and its tumors. The WHO classification. Ann NY Acad Sci 1014:13-27, 2004.

66. Morimoto R, Satoh F, Murakami O, et al: Immunohistochemistry of a proliferation marker Ki67/MIB1 in adrenocortical carcinomas: Ki67/MIB1 labeling index is a predictor for recurrence of adrenocortical carcinomas. Endocr J 55: 49-55, 2008

67. Gupta N, Srinivasan R and Rajwanshi A: Functional biomarkers in cervical precancer: an overview. Diagn Cytopathol 38: 618-623, 2010.

68. Jalava P, Kuopio T, Juntti-Patinen L, et al: Ki67 immunohistochemistry: a valuable marker in prognostication but with a risk of misclassification: proliferation subgroups formed based on Ki67 immunoreactivity and standardized mitotic index. Histopathology 48: 674-682, 2006.

69. Zhang B: Neoadjuvant endocrine therapy for postmenopausal estrogen receptor-positive patients with breast cancer. Zhonghua Zhong Liu Za Zhi 33: 241-244, 2011 (In Chinese).
70. Gentile V, Vicini P, Giacomelli L, et al: Detection of human papillomavirus DNA, p53 and ki-67 expression in penile carcinomas. Int J Immunopathol Pharmacol 19: 209-215, 2006.

71. Kroeze SG, Bijenhof AM, Bosch JL and Jans JJ: Diagnostic and prognostic tissuemarkers in clear cell and papillary renal cell carcinoma. Cancer Biomark 7: 261-268, 2010.

72. D'Angelo E and Prat J: Uterine sarcomas: a review. Gynecol Oncol 116: 131-139, 2010

73. Yu JY, DeRuiter SL and Turner DL: RNA interference by expression of short-interfering RNAs and hairpin RNAs in mammalian cells. Proc Natl Acad Sci USA 99: 6047-6052, 2002.

74. Li L, Thomas RM, Suzuki H, et al: A small molecule Smac mimic potentiates TRAIL- and TNFalpha-mediated cell death Science 305: 1471-1474, 2004.

75. Ben-Izhak O, Bar-Chana M, Sussman L, et al: Ki67 antigen and PCNA proliferation markers predict survival in anorectal malignant melanoma. Histopathology 41: 519-525, 2002.

76. Hu HY, Liu H, Zhang JW, et al: Clinical significance of Smac and Ki-67 expression in pancreatic cancer. Hepatogastroenterology 59: 2640-2643, 2012.

77. Liu YZ, Jiang YY, Hao JJ, et al: Prognostic significance of MCM7 expression in the bronchial brushings of patients with non-small cell lung cancer (NSCLC). Lung Cancer 77: 176-182, 2012.

78. Golmohammadi R and Pejhan A: The prognostic value of the P53 protein and the Ki67 marker in breast cancer patients. J Pak Med Assoc 62: 871-875, 2012.

79. Tihan T, Davis R, Elowitz E, et al: Practical value of Ki-67 and p53 labeling indexes in stereotactic biopsies of diffuse and pilocytic astrocytomas. Arch Pathol Lab Med 124: 108-113, 2000.

80. Iamaroon A, Khemaleelakul U, Pongsiriwet S and Pintong J: Co-expression of p53 and Ki67 and lack of EBV expression in oral squamous cell carcinoma. J Oral Pathol Med 33: 30-36, 2004.

81. Boonyaphiphat P, Pruegsanusak K and Thongsuksai P: The prognostic value of $\mathrm{p} 53, \mathrm{Bcl}-2$ and $\mathrm{Bax}$ expression in laryngeal cancer. J Med Assoc Thai 95: 1317-1320, 2012.

82. Tadbir AA, Pardis S, Ashkavandi ZJ, et al: Expression of Ki67 and CD105 as proliferation and angiogenesis markers in salivary gland tumors. Asian Pac J Cancer Prev 13: 5155-5159, 2012.

83. Chen JX, Deng N, Chen X, et al: A novel molecular grading model: combination of Ki67 and VEGF in predicting tumor recurrence and progression in non-invasive urothelial bladder cancer. Asian Pac J Cancer Prev 13: 2229-2234, 2012.

84. Hoogerbrugge N, Hermens RP, Nagengast F, et al: Tumour examination to detect hereditary colorectal cancer. Ned Tijdschr Geneeskd 156: A4982, 2012 (In Dutch)

85. Nabi U, Nagi AH and Sami W: Ki-67 proliferating index and histological grade, type and stage of colorectal carcinoma. J Ayub Med Coll Abbottabad 20: 44-48, 2008.

86. Tvedskov TF: Staging of women with breast cancer after introduction of sentinel node guided axillary dissection. Dan Med J 59: B4475, 2012.

87. Wang MJ, Pei DS, Qian GW, et al: p53 regulates Ki-67 promoter activity through p53-and Sp1-dependent manner in HeLa cells. Tumour Biol 32: 905-912, 2011

88. Grala B, Markiewicz T, Kozowski W, et al: New automated image analysis method for the assessment of Ki-67 labeling index in meningiomas. Folia Histochem Cytobiol 47: 587-592, 2009.

89. Tuominen VJ, Ruotoistenmäki S, Viitanen A, et al: ImmunoRatio: a publicly available web application for quantitative image analysis of estrogen receptor (ER), progesterone receptor (PR), and Ki-67. Breast Cancer Res 12: R56, 2010.

90. Gilles FH, Tavaré CJ, Becker LE, et al: Pathologist interobserver variability of histologic features in childhood brain tumors: results from the CCG-945 study. Pediatr Dev Pathol 11: 108-117, 2008.

91. Grzybicki DM, Liu Y, Moore SA, et al: Interobserver variability associated with the MIB-1 labeling index: high levels suggest limited prognostic usefulness for patients with primary brain tumors. Cancer 92: 2720-2726, 2001.

92. Hsu CY, Ho DM, Yang CF and Chiang H: Interobserver reproducibility of MIB-1 labeling index in astrocytic tumors using different counting methods. Mod Pathol 16: 951-957, 2003.

93. Walker RA: Quantification of immunohistochemistry - issues concerning methods, utility and semiquantitative assessment I. Histopathology 49: 406-410, 2006.

94. Bertucci F, Finetti P, Roche H, et al: Comparison of the prognostic value of genomic grade index, Ki67 expression and mitotic activity index in early node-positive breast cancer patients. Ann Oncol 24: 625-632, 2013 
95. Nielsen PS, Riber-Hansen R, Raundahl J and Steiniche T: Automated quantification of MART1-verified Ki67 indices by digital image analysis in melanocytic lesions. Arch Pathol Lab Med 136: 627-634, 2012.

96. Nielsen PS, Riber-Hansen R, and Steiniche $T$ : Immunohistochemical double stains against Ki67/MART1 and HMB45/MITF: promising diagnostic tools in melanocytic lesions. Am J Dermatopathol 33: 361-370, 2011.

97.Petit T, Wilt M, Velten M, et al: Comparative value of tumour grade, hormonal receptors, $\mathrm{Ki}-67, \mathrm{HER}-2$ and topoisomerase II alpha status as predictive markers in breast cancer patients treated with neoadjuvant anthracycline-based chemotherapy. Eur J Cancer 40:205-211, 2004.

98. Chang J, Ormerod M, Powles TJ, et al: Apoptosis and proliferation as predictors of chemotherapy response in patients with breast carcinoma. Cancer 89:2145-2152, 2000.

99. Viale G, Giobbie-Hurder A, Regan MM, et al: Prognostic and predictive value of centrally reviewed $\mathrm{Ki}-67$ labeling index in postmenopausal women with endocrine-responsive breast cancer: results from Breast International Group Trial 1-98 comparing adjuvant tamoxifen with letrozole. J Clin Oncol 26 5569-75, 2008.

100. Yerushalmi R, Woods R, Ravdin PM, et al: Ki67 in breast cancer: prognostic and predictive potential. Lancet Oncol 11: 174-183, 2010

101.Park JY, Kim KR, and Nam JH: Immunohistochemical analysis for therapeutic targets and prognostic markers in low-grade endometrial stromal sarcoma. Int J Gynecol Cancer 23: 81-89, 2013

102. Nagao K, Yamamoto Y, Hara T, et al: Ki67 and BUBR1 may discriminate clinically insignificant prostate cancer in the PSA range $<4 \mathrm{ng} / \mathrm{ml}$. Jpn J Clin Oncol 41: 555-564, 2011.

103. Machowska M, Wachowicz K, Sopel M, et al: Nuclear location of tumor suppressor protein maspin inhibits proliferation of breast cancer cells without affecting proliferation of norma epithelial cells. BMC Cancer 14:142, 2014.

104. Nielsen PS, Riber-Hansen R, Jensen TO, et al: Proliferation indices of phosphor-histone $\mathrm{H} 3$ and Ki67: strong prognostic markers in a consecutive cohort with stage I/II melanoma. Mod Pathol 26(3):404-13, 2013

105. Vogt $\mathrm{N}$ and Klapper W: Variability in morphology and cell proliferation in sequential biopsies of mantle cell lymphoma at diagnosis and relapse: clinical correlation and insights into disease progression. Histopathology 62: 334-342, 2013

106. Palmqvist R, Sellberg P, Oberg A, et al: Low tumour cell proliferation at the invasive marginis associated with a poor prognosis in Dukes' stage B colorectal cancers. Br. J. Cancer; 79 577-581,1999.

107. Kimura T, Tanaka S, Haruma K et al: Clinical significance of MUC1 and E-cadherin expression, cellular proliferation, and angiogenesis at the deepest invasive portion of colorectal cancer. Int J Oncol 16: 55-64,2000

108. Holdcraft J and Gallagher JC: Malignant melanomas of the nasal and paranasal sinus mucosa. Ann Otol Rhinol Laryngol 78: 5-20, 1969.

109. Rinaldo A, Shaha AR, Patel SG and Ferlito A: Primary mucosal melanoma of the nasal cavity and paranasal sinuses. Acta Otolaryngol 121: 979-982, 2001.

110. Bisgaard ML: Young age colorectal cancer and identification of hereditary non-polyposis colorectal cancer cohorts. Br J Surg 94: 1055-1056, 2007.
111. Niezabitowski A, Czajecki K, Ryś J, et al: Prognostic evaluation of cutaneous malignant melanoma: a clinicopathologic and immunohistochemical study. J Surg Oncol 70: 150-160, 1999.

112. Tuleta I, Bauriedel G, Steinmetz M, et al: Apoptosis-regulated survival of primarily extravascular cells in proliferative active poststent neointima. Cardiovasc Pathol 19: 353-360, 2010.

113. Wajed SA, Laird PW and DeMeester TR: DNA methylation: an alternative pathway to cancer. Ann Surg 234:10-20,2001.

114. Zheng JN, Ma TX, Cao JY, et al: Knockdown of Ki-67 by small interfering RNA leads to inhibition of proliferation and induction of apoptosis in human renal carcinoma cells. Life Sci 78: 724-729, 2006.

115. Zheng JN, Sun YF, Pei DS, et al: Anti-Ki-67 peptide nucleic acid affects the proliferation and apoptosis of human renal carcinoma cells in vitro. Life Sci 76:1873-1881, 2005.

116. Chan JH, Lim S and Wong WS: Antisense oligonucleotides: from design to therapeutic application. Clin Exp Pharmacol Physiol 33: 533-540, 2006.

117. Paulasova $\mathrm{P}$ and Pellestor F: The peptide nucleic acids (PNAs): a new generation of probes for genetic and cytogenetic analyses. Ann Genet 47: 349-358, 2004.

118. Smolina IV and Demidov VV: Sequence-universal recognition of duplex DNA by oligonucleotides via pseudocomplementarity and helix invasion. Chem Biol 10: 591-595, 2003.

119. Demidov VV and Frank-Kamenetskii MD: Two sides of the coin: affinity and specificity of nucleic acid interactions. Trends Biochem Sci 29: 62-71, 2004.

120. Demidov VV, Potaman VN, Frank-Kamenetskii MD, et al: Stability of peptide nucleic acids in human serum and cellular extracts. Biochem Pharmacol 48: 1310-1313, 1994

121. Tuschl T: RNA interference and small interfering RNAs. Chembiochem 2: 239-245, 2001.

122. Zheng JN, Pei DS, Mao LJ, et al: Inhibition of renal cancer cell growth in vitro and in vivo with oncolytic adenovirus armed short hairpin RNA targeting Ki-67 encoding mRNA. Cancer Gene Ther 16: 20-32, 2009.

123. Pai SI, Lin YY, Macaes B, Meneshian A, Hung CF and Wu TC: Prospects of RNA interference therapy for cancer. Gene Ther 13: 464-477, 2006.

124. Brummelkamp TR, Bernards R and Agami R: A system for stable expression of short interfering RNAs in mammalian cells. Science 296: 550-553, 2002.

125. Lieberman J, Song E, Lee SK and Shankar P: Interfering with disease: opportunities and roadblocks to harnessing RNA interference. Trends Mol Med 9:397-403, 2003.

126. Moore CB, Guthrie EH, Huang MT and Taxman DJ: Short hairpin RNA (shRNA): design, delivery, and assessment of gene knockdown. Methods Mol Biol 629: 141-158, 2010.

127.Zhu H, Guo W, Zhang L, et al: Bcl-XL small interfering RNA suppresses the proliferation of 5-fluorouracil-resistant human colon cancer cells. Mol Cancer Ther 4: 451-456, 2005.

128. Starborg M, Gell K, Brundell E and Höög C: The murine Ki-67 cell proliferation antigen accumulates in the nucleolar and heterochromatic regions of interphase cells and at the periphery of the mitotic chromosomes in a process essential for cell cycle progression. J Cell Sci 109: 143-153, 1996.

129. Zhang P, Steelant W, Kumar M and Scholfield M: Versatile photosensitizers for photodynamic therapy at infrared excitation. J Am Chem Soc 129: 4526-4527, 2007. 